AI-Manhaj: Journal of Indonesian Islamic Family Law, 2 (2), 2020: 97-109

ISSN: 2715-003; E-ISSN 2714-5514

DOI: http://dx.doi.org/10.19105/al-manhaj.v1i1.3722

\title{
Kewarisan Anak Dari Pernikahan Dengan Ahlul Kitab (Studi Kasus di Kelurahan Kedung Cowek Kecamatan Bulak Kota Surabaya)
}

\author{
Fahruddin Amanul Ilmi \\ (Institut Agama Islam Negeri (IAIN) Madura, email: fahamami12@gmail.com)
}

\begin{abstract}
Abstrak:
Fokus penelitian kajian ini, pertama, Bagaimana kewarisan anak dari pernikahan dengan ahlul kitab di Kelurahan Kedung Cowek Kecamatan Bulak Kota Surabaya? Kedua, apa hambatan hak mewaris anak yang lahir dari perkawinan beda agama? Ketiga, bagaimana pandangan hukum Islam terhadap kewarisan anak dari pernikahan dengan ahlul kitab Kelurahan Kedung Cowek kecamatan Bulak Kota Surabaya? Penelitian ini menggunakan pendekatan kualitatif dengan jenis deskriptif. Hasil penelitian ini, pertama, kewarisan anak dari pernikahan dengan ahlul kitab di kelurahan Kedung Cowek kecamatan Bulak Kota Surabaya terlaksana namun sebagian tidak terlaksana. Kedua, Hambatan hak mewaris anak yang lahir dari perkawinan beda agama adalah belum adanya payung hukum yang mengaturnya. Ketiga, pandangan hukum Islam terhadap kewarisan anak dari pernikahan dengan ahlul kitab kelurahan Kedung Cowek kecamatan Bulak Kota Surabaya adalah haram. (The research focus of this study is, first, how is the inheritance of children from marriage with a man of the book in Kedung Cowek Village, Bulak District, Surabaya City? Second, what are the obstacles to the inheritance rights of children born from interfaith marriages? Third, what is the view of Islamic law on the inheritance of a child from marriage with the man of the book Kedung Cowek Village, Bulak District, Surabaya City? This research uses a qualitative approach with a
\end{abstract}


descriptive type. The results of this study, first, the inheritance of a child from marriage with a man of the book in Kedung Cowek village, Bulak sub-district, Surabaya City was implemented but partially not implemented. Second, the obstacle to the inheritance rights of children born from interfaith marriages is the absence of a legal umbrella regulating it. Third, the view of Islamic law on the inheritance of a child from marriage with the man of the book of Kedung Cowek sub-district, Bulak sub-district, Surabaya City is haram.)

\title{
Kata Kunci:
}

\author{
Kewarisan, Pernikahan Dengan Ahlul Kitab
}

\section{Pendahuluan}

Masalah harta warisan biasanya menjadi sumber sengketa dalam keluarga. Terutama apabila menentukan, siapa yang berhak dan siapa yang tidak berhak untuk mendapatkan kewarisan apabila berhak, seberapa banyak hak kewarisan yang diperolehnya.

Hal ini menimbulkan perselisihan dan akhirnya menimbulkan keretakan keluarga. Sementara orang ingin berlaku seadil-adilnya, namun tetap saja dianggap tidak adil. Oleh karena itu datanglah Islam membawa ketentuan dari Allah SWT dalam hal waris-mewaris ini. Sehingga apabila orang-orang telah dilandasi ketaqwaan kepada Allah SWT. Semuanya akan berjalan lancar, tidak akan menimbulkan sengketa, bahkan kerukunan keluargapun akan dicapai. ${ }^{1}$

Dalam beberapa literatur hukum Islam ditemui beberapa istilah untuk hukum kewarisan, seperti fiqh mawaris, ilmu faraidh dan hukum kewarisan. Perbedaan dalam penamaan ini terjadi karena perbedaan arah yang dijadikan titik utama dalam pembahasan. Fiqh mawaris adalah kata yang berasal dari bahasa arab fiqh dan mawaris. ${ }^{2}$

\footnotetext{
hlm, 4

1 Suabi Tholib, Ilmu Figh, Cet II, (Jakarta: Departemen Agama, 1986),

2 Abdul Wahid, Hukum Kewarisan Islam Sebagai Pembaruan Hukum Positif Indonesia, (Jakarta: Sinar Grafika, 2009) Hlm, 5
} 
Dan untuk mengetahui lebih lanjut sebaiknya terlebih dahulu kita mengetahui tentang pengertian fiqh mawaris itu.

Fiqh menurut bahasa berarti mengetahui, memahami, yakni mengetahui sesuatu atau memahami sesuatu sebagai hasil usaha mempergunakan pikiran yang sungguh-sungguh. Adapun kata mawaris diambil dari bahasa arab. Mawaris bentuk jamak dari miraats yang berarti harta peninggalan yang diwarisi oleh ahli waris.

Jadi fiqh mawaris adalah suatu disiplin ilmu yang membahas tentang harta peninggalan, tentang bagaimana proses pemindahan, siapa saja yang berhak menerima harta peninggalan itu serta berapa bagian masing-masing. ${ }^{3}$ Akan tetapi harta warisan menurut hukum Islam ialah segala sesuatu yang ditinggalkan oleh pewaris yang secara hukum dapat beralih kepada ahli warisnya. Dalam pengertian ini dapat dibedakan antara harta warisan dan harta peninggalan. Harta peninggalan adalah semua yang ditinggalkan oleh si mayyit atau dalam arti apa-apa yang ada pada seseorang saat kematiannya; sedangkan harta warisan ialah harta peninggalan yang secara hukum syara' berhak diterima oleh ahli waris.

Karena sesungguhnya tidak keseluruhan dari "apa yang di tinggalkan" pewaris itu menjadi hak ahli waris dapat dipahami dari dikaitkannya pelaksanaan pembagian warisan kepada beberapa tindakan yang mendahuluinya. ${ }^{4}$ Sejumlah ketentuan tentang kewarisan telah diatur secara jelas di dalam Al-Qur'an yaitu dalam surat An-nisa' ayat 7:

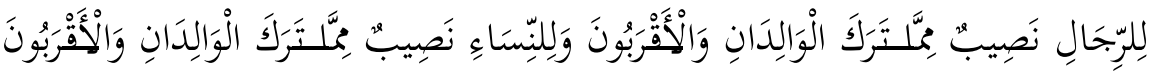

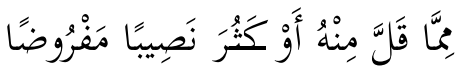

Artinya : Bagi orang laki-laki ada hak bagian dari harta peninggalan orang tau dan kerabatnya, dan bagi orang wanita ada hak bagian (pula) dari harta peninggalan orang tua dan kerabatnya, baik sedikit atau banyak menurut bagian yang telah ditetapkan. (An-nisa' ayat 7). ${ }^{5}$

\footnotetext{
${ }^{3}$ Abdul Wahid, Hukum Kewarisan Islam..., hlm 7

${ }^{4}$ Amir Syarifuddin, Hukum Kewarisan Islam, Cet IV (Jakarta: Kencana, 2012), Hlm. 208-209

5 Aisyah, Al-Qur'an Dan Terjemah Untuk Wanita, (Jakarta: Penerbit Jabal, 2010) hlm 78
} 
Untuk memudahkan pencarian terhadap sumber-sumber hukum waris di atas, dalam konteks hukum positif Indonesia, itu termuat didalam INPRES No. 1 Tahun 1991 tentang Kompilasi Hukum Islam, Buku II tentang hukum kewarisan. ${ }^{6}$ Namun bagi ummat Islam melaksanakan syariat yang ditunjukkan oleh nash-nash yang sharih dalam keharusan. Oleh sebab itu pelaksanaan waris berdasarkan hukum waris Islam bersifat wajib.

Apabila dianalisis ketentuan hukum waris Islam, yang menjadi sebab seseorang itu mendapatkan warisan dari si mayyit (ahli waris) dikarenakan ada hubungan perkawinan seseorang dapat memperoleh harta warisan (menjadi ahli waris) disebabkan adanya hubungan perkawinan antara si mayyit dengan seseorang tersebut dan juga disebabkan adanya hubungan sedarah karena seseorang dapat memperoleh harta warisan (menjadi ahli waris) disebabkan adanya hubungan nasab atau hubungan darah/kekeluargaan dengan si mayyit. ${ }^{7}$

Hubungan antara kerabat yang berbeda agama dalam kehidupan sehari-hari hanya terbatas pada pergaulan hubungan baik dan tidak menyangkut pelaksanaan agama. Petunjuk yang pasti dalam Al-Qur'an tentang hak kewarisan antara orang yang berbeda agama memang tidak ada. Tetapi hubungan perkawinan antara laki-laki dan perempuan non muslim ada di jelaskan dalam Al-Qur'an yaitu pada QS. Al-Maidah ayat 5 yang bunyinya:

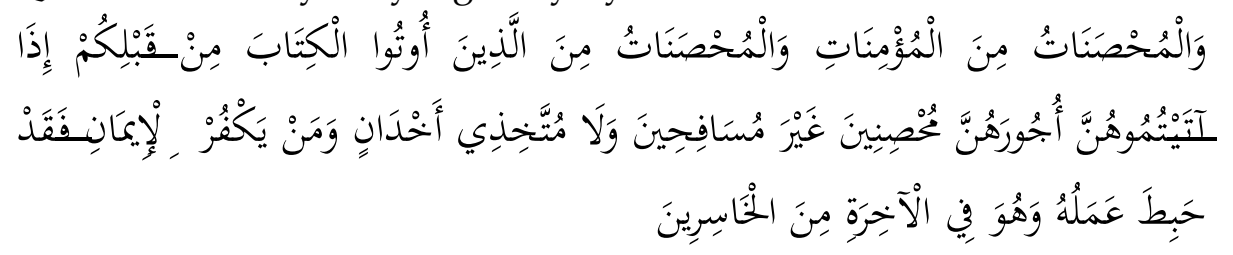

Artinya: (Dan dihalalkan mangawini) wanita yang menjaga kehormatan diantara wanita-wanita yang beriman dan wanita-wanita yang menjaga kehormatan di antara orang-orang yang diberi Al Kitab sebelum kamu, bila kamu telah membayar mas kawin mereka dengan maksud menikahinya, tidak dengan maksud berzina dan tidak (pula)

\footnotetext{
${ }^{6}$ Mustofa Haffas, Hukum Waris Islam, (Bandung: PT Refika Aditama, 2010), hlm. 3

7 Suhrawardi K. Lubis, Hukum Waris Islam, (Jakarta: Sinar Grafika, 2013), hlm. 55
} 
menjadikannya gundik-gundik. Barangsiapa yang kafir sesudah beriman (tidak menerima hukum-hukum Islam) maka hapuslah amalannya dan ia di hari kiamat termasuk orang-orang merugi. ${ }^{8}$

Fokus penelitian kajian ini, pertama, Bagaimana kewarisan anak dari pernikahan dengan ahlul kitab di Kelurahan Kedung Cowek Kecamatan Bulak Kota Surabaya? Kedua, apa hambatan hak mewaris anak yang lahir dari perkawinan beda agama? Ketiga, bagaimana pandangan hukum Islam terhadap kewarisan anak dari pernikahan dengan ahlul kitab kelurahan Kedung Cowek kecamatan Bulak Kota Surabaya?

\section{Metode Penelitian}

Penelitian ini merupakan penelitian yang menggunakan pendekatan kualitatif, yaitu prosedur penelitian yang menghasilkan data deskriptif berupa kata-kata tertulis atau lisan dari orang yang kita wawancarai. Merujuk pada bukunya Lexy J. Moelong bahwa pendekatan kualitatif adalah penelitian yang menggunakan latar alamiah dengan maksud menafsirkan fenomena yang terjadi dan dilakukan dengan jalan melibatkan berbagai metode yang ada. ${ }^{9}$ Namun pendekatan yang peniliti gunakan adalah pendekatan kualitatif. Sehingga di harapkan dapat menghasilkan data deskriptif berupa data-data tentang masalah yang peniliti teliti, yaitu kewarisan anak dari hasil pernikahan dengan ahlul kitab.

Kehadiran peneliti dalam penelitian ini adalah sebagai pengamat (peneliti) yang terjun langsung ke lapangan. Adapun yang menjadi subjek dalam penelitian ini adalah orang kristiani yang salaf dan tidak mau dari kitab injil yang dari zaman sekarang, Kehadiran peneliti di lapangan diketahui oleh subyek penelitian, karena peneliti merupakan salah satu tetangga dari keluarga tersebut, Selain itu, peneliti juga telah meminta izin dan telah menerangkan maksud dan tujuan yang akan peneliti lakukan. hal ini sangat membantu peneliti dalam proses penggalian data dalam rangka menyelesaikan skripsi

8 Aisyah, Al-Qur'an Dan Terjemah Untuk Wanita, hlm 108

9 Lexy J. Moelong, Metodologi Penelitian Kualitatif, (Bandung: PT. Remaja Rosdakarya, 2013), hlm. 4. 
yang sedang peneliti lakukan. Jadi penelitian mutlak di perlukan karena peneliti adalah tetangga dari keluarga tersebut.

Langkah awal yang dilakukan seorang peneliti sebelum mengambil dan menganalisis data adalah mengetahui dan menemukan lokasi yang menjadi penelitian. Adapun lokasi penelitin ini adalah Surabaya tempatnya di kelurahan Kedung Cowek kecamatan Bulak. Adapun alasan pemilihan lokasi penelitian adalah Peneliti memilih tempat tersebut disebabkan ada pembagian waris yang dari hasil pernikahann dengan ahlul kitab.

\section{Konsep Kewarisan menurut Islam}

Kewarisan menurut hukum Islam ialah segala sesuatu yang ditinggalkan oleh pewaris yang secara hukum dapat beralih kepada ahli warisnya. Dalam pengertian ini dapat dibedakan antara harta warisan dan harta peninggalan. Harta peninggalan adalah semua yang ditinggalkan oleh si mayyit atau dalam arti apa-apa yang ada pada seseorang saat kematiannya; sedangkan harta warisan ialah harta peninggalan yang secara hukum syara' berhak diterima oleh ahli waris. Karena sesungguhnya tidak keseluruhan dari "apa yang di tinggalkan" pewaris itu menjadi hak ahli waris dapat dipahami dari dikaitkannya pelaksanaan pembagian warisan itu kepada beberapa tindakan yang mendahuluinya ${ }^{10}$

Ada lima hak yang berkaitan dengan harta waris, hak itu perlu diketahui terutama bagi mereka yang akan membagikan harta waris kepada ahli warisnya. Sedangkan cara penerapan hak-hak yang yang berkaitan dengan harta tersebut terhadap harta waris itu sebagai berikut: ${ }^{11}$

Pertama, Setiap hak yang berhubungan langsung dengan harta yang di tinggal mayyit.

Kedua, Biaya penguburan si mayyit.

Ketiga, Hutang si mayyit.

10 Amir Syarifuddin, Hukum Kewarisan Islam, Cet. IV, (Jakarta: Kencana, 2012), hlm. 208-209

${ }^{11}$ Segaf Hasan Baharun, Bagaimanakah Anda Membagikan Harta Warisan Dengan Benar, (Bangil: Yayasan Pondok Pesantren Darulloghoh Wadda'wah, 2007), hlm 4 
Ketiga, Wasiat si mayyit.

Keempat, Pembagian harta waris untuk ahli waris.

\section{Dasar dan Sumber Hukum Kewarisan}

Dasar dan sumber utama dari hukum Islam, sebagai hukum agama (I1`slam) adalah nash atau teks yang terdapat dalam al-qur'an dan sunnah Nabi. ${ }^{12}$ Ayat-ayat Al-Qur'an dan Hadist nabi yang secara langsung mengatur kewarisan itu adalah sebagai berikut:

QS. Al-Nisa (4): 7

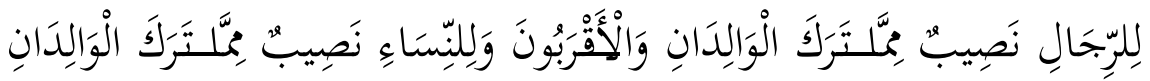

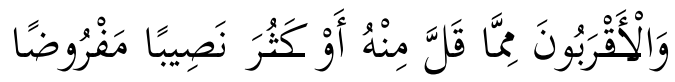

Artinya : Bagi laki-laki ada hak bagian dari harta peninggalan kedua orang tua dan kerabatnya, dan bagi perempuan ada hak bagian pula dari harta peninggalan kedua orang tua dan kerabatnya, baik sedikit atau banyak, (semua itu merupakan) bagian yang telah ditentukan.

Hadist Nabi Muhammad SAW yang secara langsung mengatur warisan salah satunya adalah hadist Nabi dari ibnu Abbas menurut riwayat imam Bukhari

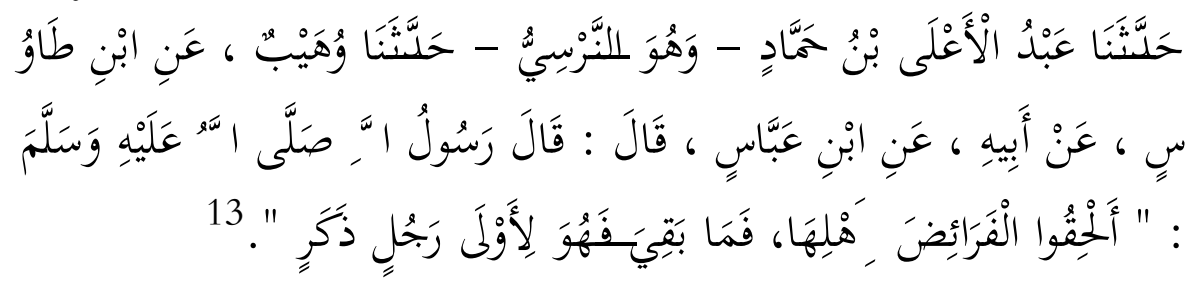

Artinya : Rasulullah saw. Bersabda: "Jangan ikuti kewajiban wajib dari keluarga keluarga. Yang tersisa adalah untuk pria pertama." Diriwayatkan oleh Ibnu Abbas, atas wibawa ayahnya, atas kewibawaan Ibnu Abbas.

12 Amir Syarifuddin, "Hukum Kewarisan Islam",Cetakan kedua, (Jakarta: Kencana, 2005), hlm. 7

${ }_{13}$ Muslim ibn Hajjaj, Shahih Muslim, juz II, (Semarang: CV. Usaha Keluarga, tt.) hlm 3 


\section{Unsur - Unsur Kewarisan}

Untuk terjadinya pewarisan harus memenuhi beberapa unsur, yaitu: ${ }^{14}$ yang mewariskan atau Pewaris, Ketentuan tentang pewaris, Harta warisan dan Ahli Waris.

Sebab Sebab Kewarisan

Salah satu hal yang terpenting dalam mempelajari hukum waris Islam adalah menyang kut waris, kalau ditinggal dari segi asal kata, perkataan waris berasal dari bahasa arab yaitu warist, secara gramatikal berarti yang ditinggal atau yang kekal. Maka dari itu yang menjadi sebab seseorang itu mendapatkan warisan dari si mayit (ahli waris) dapat diklasifikasikan sebagai berikut;

Satu, Hubungan Perkawinan

Dua, Hubungan Darah

Tiga, Karena Memerdekakan Si Mayit

Empat, Karena Sesama Islam

\section{Halangan Kewarisan}

Adapun halangan terlaksanya waris mawaris dalam istilah ulama' faraid ialah suatu keadaan / sifat yang menyebabkan orang tersebut tidak dapat menerima warisan padahal sudah cukup syaratsyarat dan ada hubungan pewarisan. Dalam hal hukum kewarisan Islam yang menjadi penghalang bagi seseorang ahli waris untuk mendapatkan warisan disebabkan karena hal-hal berikut: Pembunuhan, Berlainan Agama dan Perbudakan

Syarat Syarat Kewarisan

Dalam syariat Islam ada tiga syarat supaya pewarisan dinyatakan ada, sehingga dapat memberi hak kepada seeorang atau ahli waris untuk menerima warisan, yaitu:

Pertama, Orang yang mewariskan (muwaris) benar telah meninggal dunia dan dapat dibuktikan secara hukum bahwa ia telah meninggal.

14 Amir Syarifuddin, Hukum Kewarisan Islam, Cet IV, (Jakarta: Kencana, 2012), hlm. 205 
Kedua, Orang yang mewarisi (ahli waris atau waris) hidup pada saaat orang yang mewariskan meninggal dunia dan bisa dibuktikan secara hukum.

Ketiga, Ada hubungan pewarisan antara orang yang mewariskan dengan orang yang mewarisi, yaitu:

Hubungan nasab.

Hubungan pernikahan.

Hubungan perbudakan (wala'). ${ }^{15}$

\section{Monografi Desa Kedung Cowek}

Deskripsi lokasi dan wilayah penjabaran penduduk perlu dipastikan ciri-ciri gegrafisnya meliputi sifat daerah, yaitu kondisi geografis, demografi dan sebagainya. Desa Kedung Cowek termasuk wilayah Kecamatan Bulak Kota Surabaya letaknya berdekatan dengan jalan raya Surabaya - Madura. Jarak antara Kedung Cowek dengan kota Surabaya sekitar $30 \mathrm{~km}$.

Kecamatan Bulak Surabaya terletak di Desa Kedung Cowek, jadi semua penyelenggaraan aktifitas Kecamatan Bulak Kota Surabaya berbatasan sebagai berikut:

Sebelah Utara : Selat Madura

Sebelah Selatan : Kedinding

Sebelah Timur : Cumpat

Sebelah Barat : : Bulak Banteng

Setiap masyarakat mempunyai pandangan hidup dan hal itu juga pada masyarakat Kedung Cowek. Umumnya pandangan hidup masyarakat Kelurahan mengangkat eksistensi manusia di dunia dalam hubungannya dengan Tuhan, dengan sesama manusia juga dengan alam tempat mereka berdiam. Pada dasarnya apa yang disebut hidup ini berkaitan erat dengan sikap manusia terhadap Tuhan-nya, sesamanya dan terhadap dunia sekitar.

Pandangan masyarakat Kedung Cowek yang paling nampak adalah bahwa masyarakat Kedung Cowek dalam pandangan hidup menjadi dua, sesuai dengan masyarakat Kedung Cowek:

${ }^{15}$ Amin Husein Nasution, Hukum Kewarisan Suatu Analisis Komparatif Pemikiran Mujtahid Dan Kompilasi Hukum Islam, (jakarta: Rajawali Pers, 2012) hlm 71-77 
Masyarakat yang masih berada dalam garis kemiskinan.

Masyarakat di Kedung Cowek sulit sekali untuk mengubah dirinya ke arah yang lebih baik, semua itu disebabkan selain karena rendahnya pendidikan mereka walaupun masyarakat Kedung Cowek mempunyai etos kerja yang sangat baik tetapi hal itu tidak di lengkapi oleh skill dan keterampilan yang mewadahi.

Masyarakat yang sudah bisa mengentaskan diri dari lingkaran kemiskinan.

Masyarakat ini tergolong masyarakat yang berfikiran maju, yang mengubah dirinya kea rah yang lebih baik, baginya hidup adalah sebuah perjuangan yang harus dihadapi dengan keterampilan tertentu dan bukan untuk dihindari.

\section{Temuan Peneliti}

Setelah peneliti melakukan penelitian dengan mengumpulkan data kemudian mempaparkan sesuai dengan yang diperoleh di lapangan, maka peneliti menemukan beberapa hal sebagai bentuk temuan penelitian.

Beberapa hasil temuan yang bisa dilaporkan dalam bentuk tulisan ini meliputi sebagai berikut:

Pelaksanaan pembagian kewarisan dari pernikahan dengan ahlul kitab di Kedung cowek ada klasifikasi. Pertama, anak tersebut tidak memperoleh warisan dan yang kedua, anak memperoleh warisan berupa rumah dan sawah dengan cara si anak menentukan bagiannya sendiri. Sebagian dari mereka juga memperoleh warisan dengan melalui musyawarah untuk menentukan bagian-bagiannya agar harta tersebut bisa dibagi rata kepada anak-anaknya dan juga agar tidak ada masalah dan percekcokan keluarga. Dalam musyawarah tersebut kepada semua ahli waris, menunjukkan bahwa harta yang dimilikinya ada dimana saja dan berapa perolehannya agar bisa dibagi rata kepada semua ahli waris.

Masalah hambatan bagi anak dari pernikahan dengan ahlul kitab itu ada yang tidak membolehkan masalah pembagian warisan yang hasil dari pernikahan dengan ahlul kitab itu disebabkan beliau seorang non muslim namun hal itu tetap dilakukan sebab mereka masih anaknya kandung. Di kelurahan Kedung 
cowek banyak warga yang berbeda agama dan juga ada seorang ahli kitab. namun permasalahannya warga Kedung Cowek tidak semuanya mentaati aturan hukum Islam. Bahkan (presepsi penulis) mereka lebih mengutamakan hukum negara dibanding hukum Islam

Dalam hal anak hasil pernikahan dengan ahlul kitab telah mendapatkan warisan secara penuh Rasullulah saw bahwa kewarisan itu sebenarnya batal demi hukum, sebagaimana hadis:

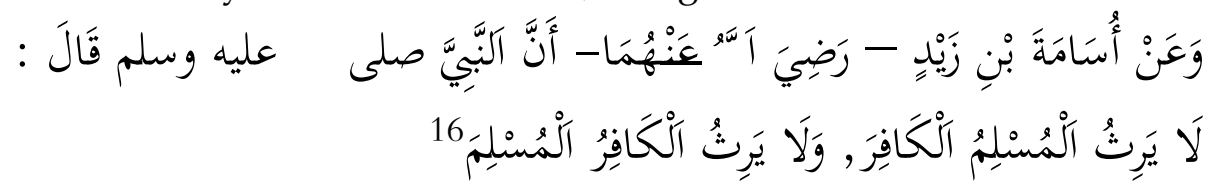

Artinya : Dari Usamah Ibnu Zaid RA bahwa Nabi SAW bersabda: “Orang muslim tidak mewarisi hata orang kafir dan orang kafir tidak mewarisi harta orang muslim."

\section{Penutup}

Berdasarkan uraian yang telah dikemukakan di atas, dapatlah diambil kesimpulan sebagai berikut :

Pertama, kewarisan anak dari pernikahan dengan ahlul kitab di kelurahan Kedung Cowek kecamatan Bulak Kota Surabaya terlaksana melalui musyawarah keluarga untuk menentukan bagian-bagiannya namun sebagian tidak terlaksana.

Kedua, Hambatan hak mewaris anak yang lahir dari perkawinan beda agama adalah belum adanya payung hukum yang mengaturnya.

Ketiga, pandangan hukum Islam terhadap kewarisan anak dari pernikahan dengan ahlul kitab kelurahan Kedung Cowek kecamatan Bulak Kota Surabaya adalah haram.

\section{Daftar Pustaka}

Abdurrahman, Sayyid, Bughyah al-Musytarsidin, tt. Aisyah, Al-Qur'an Dan Terjemah Untuk Wanita, Jakarta: Penerbit Jabal, 2010

Al Barry, M.Dahlan, Kamus Ilmiah Populer, Surabaya: Arkola, 2001

16 Imam Abi Abdullah Muhammad ibn Ismail Bukhariy, Fathul Bari, Juz 8 ( Al-Tawkiyya, 2008) hlm. 156 
Arikunto, Suharsimi, Prosedur Penelitian Suatu Pendekatan Praktek, Jakarta, Rineka Cipta, 2006

Basyir, Azar Ahmad, Hukum Waris Islam, yogyakarta: UII pres, 2004

Bukhariy, Imam Abi Abdullah Muhammad Bin Ismail, Fath al-Bari: AlTawkiyya, 2008

Buna'i, Penelitian Kualitatif, Pamekasan: Fo Press, 2008

Bungin, M. Burhan, Penelitian Kualitatif, Jakarta: Prenada Media Group, 2007

Al-Darimiy, Abi Muhammad Abdullah Bin Bahar, Sunan al-Darimiy, Bairut, Dar al-Fikr, 2005

Ghony, M. Djunaidi, Metodologi Penelitian Kualitatif, Jogjakarta: ArRuzz Media, 2014

Haffas, Mustofa, Hukum Waris Islam, Bandung: PT Refika Aditama, 2010

Hajjaj, Muslim ibn, Shahih Muslim, Semarang: cv. Usaha Keluarga, tt.

Hasan, Segaf, Bagaimanakah Anda Membagikan Harta Warisan Dengan Benar, Bangil: yayasan pondok pesantren darul Lughoh Wadda'wah, 2007

Ichtiyanto, Perkawinan Campuran Dalam Negara Republik Indonesia, Jakarta: Departemen Agama, 2013

Jabal, Ahmad Bin Muhammad Bin, "Musnad", Darel Hadith, 1994

Lubis, Suhrawardi, Hukum Waris Islam, Jakarta: Sinar Grafika, 2013

Moelong, Lexy J., Metodologi Penelitian Kualitatif, Bandung: PT. Remaja Rosdakarya, 2013

Mourik, Van, Studi Kasus Hukum Waris, cet 1, Bandung: Eresco, 1993

Muhammad, Al-Jabry Abdul Mataal, Perkawinan Campuran Menurut Pandangan Islam. Cet II, Jakarta: PT Bulan Bintang, 1991

Nasution, Husein Amin, Hukum Kewarisan Suatu Analisis Komperatif Pemikiran Mujtahid Dan Kompilasi Hukum Islam" jakarta: rajawali pers, 2012

Prastowo, Andi, Metode Penelitian Kualitatif dalam Perspektif Rancangan, Penelitian, Yogyakarta: Ar-Ruzz Media, 2012

Rahman, Fatchur, Ilmu Waris, Bandung: PT Al Ma'arif, 1975

Sajjastani, Abi Daud Sulaiman ibn As'as, Sunan Abi Daud, (Darul Fikr: CV. Taufik Darusat, t.th)

Suwandi, dan Basrowi, Memahami Penelitian Kualitatif, Jakarta: Rineka Cipta, 2008 
Syarifuddin Amir, Hukum Kewarisan Islam, Cet II, Jakarta: Kencana, 2005

Syarifuddin, Amir, Hukum Kewarisan Islam, Cet IV , Jakarta: Kencana, 2012

Tim, Undang-Undang R.I. Nomor 1 Tahun 1974 Tentang Perkawinan $\mathcal{E}$ Kompilasi Hukum Islam, Bandung: citra umbara, 2015

Thalib, Sajuti, Hukum Kewarisan Islam Indonesia, Jakarta: Sinar Grafika, 2004

Tholib, Suabi, Ilmu Figh, Cet II, Jakarta: Departemen agama, 1986

Wahid, Abdul, Hukum Kewarisan Islam Sebagai Pembaruan Hukum Positif Indonesia, Jakarta: Sinar Grafika, 2009 